\title{
International Psychogeriatrics turns a new page: new editor begins his term
}

It is a great honor and a privilege to be appointed as the new Editor-in-Chief of the International Psychogeriatrics (IPG), the flagship journal of the premier international geriatric psychiatry organization - the International Psychogeriatric Association (IPA). I am a proud Life Member of the IPA, and have been involved in different activities of the IPA over the past three decades.

The IPA was founded in 1982 by my longtime friend and distinguished colleague, Sanford (Sandy) Finkel. It was then a small group of individuals whose vision included developing an organization that served a worldwide community of professionals in psychogeriatrics. Its mission would be to help advance its members' careers and improve the mental health of older people everywhere through education, research, professional development, advocacy, health promotion, and service development. (http://www.ipa-online. org/about/mission-and-vision). That vision is a reality today. IPA members include physicians (psychiatrists, neurologists, geriatricians, primary care clinicians, among others), nurses, social workers, occupational therapists, psychologists, researchers, epidemiologists, and many others. With members from over 50 countries and meetings all over the world, IPA brings together leaders from different backgrounds to share their perspectives, form policy, and learn from one another.

The IPG was born in 1989. Its Founding Editor was a pioneer in the field - the late Gene Cohen. Manfred Bergener and Kazuo Hasegawa were Associate Editors and Sandy Finkel the Managing Editor. In their inaugural editorial (Cohen et al., 1989), this team described its pride, excitement, and a sense of challenge in launching that first issue of the new journal. They correctly stated that "This truly is the historic moment in the fields of gerontology and geriatrics, a period marked by the coming together of societal concern and scientific curiosity about issues of aging and the problems of the elderly. It is a moment not confined to any one nation, nor to any one continent; that is what makes it all the more important and exciting." The high bar set by Gene Cohen was not just maintained but also broadened by subsequent Editors-in-Chief: Robin Eastwood (1996-2002), David Ames (2003-
2010), and most recently Nicola Lautenschlager (2011-2017). I feel fortunate to follow in the footsteps of these amazingly successful leaders in our field (Ames, 2009; Lautenschlager, 2014).

As the flagship journal of the IPA, the IPG aims to reflect the global vision and mission of the organization. It is a multidisciplinary, peer-reviewed journal for researchers, clinicians, and educators in psychogeriatrics, emphasizing an integrated and broadly encompassing approach to older people, which considers physical and mental health and illness, as well as psychosocial factors and societal perspectives.

The IPG has grown rapidly. It started with just 2 annual issues in 1989 , rose to $4-6$ issues by 2009 , 8 issues in 2010, 10 issues in 2011, finally reaching 12 issues in 2012 . Today, the IPG has nearly 450 submissions annually from across the world, with the latest Impact Factor being 2.43.

I want to take this opportunity to introduce myself to our readers, briefly outline the plans of the new team, and seek your input. I am a geriatric neuropsychiatrist, with a full-time faculty appointment at the University of California San Diego. I am a researcher, educator, clinician, and advocate for our field and our patients. My main areas of interest are serious mental illnesses in older people as well as successful psychosocial aging including positive traits and behaviors such as resilience, wisdom, and healthy lifestyle. In terms of journal editorship, I completed a 15year-term as the Editor-in-Chief of the American Journal of Geriatric Psychiatry (AJGP) ending in 2015 (Jeste, 2016). When I assumed its editorship, the AJGP was a quarterly with fewer than 100 submissions per year, mostly from within the USA, and its impact factor was less than 2. During the subsequent 15 years, thanks to strong support and help from a variety of stakeholders, the AJGP more than tripled the number of submissions per year, two-thirds of them from outside the USA, and its impact factor rose to be the highest among all the geriatric journals in the world - i.e. not just geriatric psychiatry but also those in geriatric medicine overall. I humbly hope that I can also help the IPG continue and accelerate its successful trajectory. 
I am thrilled to announce the new Editorial Board that includes several members from the previous Board while adding a number of new ones. The Deputy Editors are Gill Livingston, Henry Brodaty, and Kostas Lyketsos. The fourth Deputy Editor is the Statistical Editor, Steve Arndt, who will review most of the quantitative databased manuscripts to ensure a high quality of analyses and methodologies across articles. The Board also includes 30 Triage Editors from a number of countries covering various professions. An important new feature of the Editorial Board is the inclusion of Junior Board Members - fellows or junior faculty who, with appropriate mentorship and experience, will become the future leaders of our field. And then there are the numerous reviewers, at least two of whom review each submitted paper. Without their generous help the peer-review process would not be possible. And finally, the Board of Directors of IPA as well as the publisher, Cambridge University Press (CUP), will continue to engage with IPG in a continuous dialogue to help the journal progress further.

The new Editorial Board's goal is to preserve and enhance the gains accomplished by my distinguished predecessors. We will now collectively focus on making the IPG the premier psychogeriatric journal in the world. Working as a team, we will make our journal the leading forum for publication of cutting-edge science in aging-related mental and behavioral health and neuroscience. At the same time, the published papers must be useful to clinicians and trainees. The IPG will reflect the state-of-the-art of academic psychogeriatrics as a whole - including research, clinical practice, training, and policies. Thus, it will continue to serve all of the membership of the IPA and will also generate new membership to the IPA and new readership for the IPG. One of my initiatives will focus on developing theme-based issues, which are highly valued not only by researchers but also by trainees and clinicians.

To ensure transparency regarding ethical issues and avoidance of conflicts of interest, we will use an updated disclosure form that requires annual listing of all potential conflicts of interest and/or funding disclosures from all authors, reviewers, and members of the editorial board. The journal's website will undergo continual improvements and enhancements. Supplemental digital content will allow the journal to publish content online that otherwise could not be published in print, such as audio and video files. When needed and feasible, we will seek to provide special editing help for excellent papers from non-English-speaking countries.

We will attend to diverse areas within our field, including cultural variations and positive aspects of aging. I strongly believe that the focus on geriatric psychiatry should not be restricted to studying and treating mental illnesses in older adults. While treating psychiatric disorders will always be our primary responsibility, we must also emphasize mental health, well-being, and positive factors such as resilience, optimism, wisdom, and social support - that is the Positive Psychiatry of Aging (Jeste and Palmer, 2013). While diseases and disabilities associated with aging will continue to be a critical area of clinical care, research and education, we must also pay attention to successful cognitive and emotional aging ( $\mathrm{Li}$ et al., 2006; Scelzo et al., 2018).

I expect the IPG to make an increasingly greater impact on the field. Issues facing journals during the coming decade will include requirements for data sharing, addressing recent concerns about problems with reproducibility of behavioral science results, an emphasis on personalized medicine, discovery of new biomarkers as well as growth of technology, changes in healthcare systems, a need for illness prevention, and the future of print versus online versions of the journals. Promotion of the IPG on social media such as Twitter will be important. We will seek to increase not only the Impact Factor of the journal but also its individual articles' Altmetrics scores. Altmetrics tracks the sharing and discussion around research papers through social media sites, newspapers, government policy documents and other sources, and then uses this information to compute a score for applicable articles. In other words, it reflects the broader impact of the articles beyond citations by researchers.

My goal is to ensure that the IPG becomes and remains THE leading journal in geriatric psychiatry in the world. We will maintain the international flavor of the Journal, with different regions of the world being represented. Publishing a journal is a real team work, and my Editorial Board is eager to work collaboratively with the IPA, CUP, authors, reviewers, and readers to make the IPG a journal we can all be proud of.

\section{Conflict of interest}

None.

\section{Dilip V. Jeste}

Department of Psychiatry, University of California San

Diego, La Jolla, California, USA

Department of Neurosciences, University of California

San Diego, La Jolla, California, USA

Sam and Rose Stein Institute for Research on Aging,

University of California San Diego, La Jolla, California, USA 


\section{Acknowledgments}

This work was supported, in part, by a grant from the National Institutes of Health, Grant R01 MH094151 (PI: Dilip V. Jeste, M.D.) and the Sam and Rose Stein Institute for Research on Aging at University of California San Diego.

\section{References}

Ames, D. (2009). International psychogeriatrics comes of age. International Psychogeriatrics, 21, 1-4, doi: $10.1017 / \mathrm{s} 1041610208008144$.

Cohen, G., Bergener, M. B., Kazuo, H. and Finkel, S. I. (1989). Editorial. International Psychogeriatrics, 1, 3-4.

International Psychogeriatric Association. Mission and Vision. Available at: http:/www.ipa-online.org/about/ mission-and-vision; last accessed 30 November 2017.
Jeste, D. V. (2016). Growth of the journal from age 8 to 23 : an exciting and joyous journey for a proud guardian. The American fournal of Geriatric Psychiatry, 24, 2-5, doi: 10.1016/j.jagp.2015.11.002.

Jeste, D. V. and Palmer, B. W. (2013). Guest Editorial: a call for a new positive psychiatry of ageing. British fournal of Psychiatry, 202, 81-83.

Lautenschlager, N. T. (2014). International psychogeriatrics and the international psychogeriatric association: a successful marriage turns silver. International Psychogeriatrics, 26, 1-2, doi: $10.1017 / \mathrm{s} 1041610213001968$.

Li, C. et al. (2006). Successful aging in Shanghai, China: definition, distribution and related factors. International Psychogeriatrics, 18, 551-563.

Scelzo, A. et al. (2018). Mixed-methods quantitative-qualitative study of 29 nonagenarians and centenarians in rural Southern Italy: focus on positive psychological traits. International Psychogeriatrics (this issue). 